\title{
Review on the Effect of Shear Connectors on Composite Deck Slabs
}

\author{
Tarek Ali ${ }^{1}$, Sameh Yehia ${ }^{2}$, Mohamed El-Didamouny ${ }^{3}$
}

\author{
${ }^{1}$ Prof. of Strength \& Properties of Materials, Faculty of Engineering, Helwan University, Egypt \\ ${ }^{2}$ Associate Professor, Civil Engineering Department, Faculty of Engineering, Suez University, Egypt \\ ${ }^{3}$ Assistant Lecturer, Higher Institute of Engineering at Shorouk City, Egypt
}

Received: 25 Nov 2020; Received in revised form: 15 Dec 2020; Accepted: 18 Dec 2020; Available online: 30 Dec 2020 C 2020 The Author(s). Published by Infogain Publication. This is an open access article under the CC BY license (https://creativecommons.org/licenses/by/4.0/).

\begin{abstract}
This paper presents a review on the effect of shear connectors on composite deck slabs. Composite deck slabs consist of profile deck sheet and concrete. Several researchers have been studying the behaviour of composite slab but due to its complex behaviour yet it is not completely understood. The behaviour of composite slab directly depends on the deformability and contact strength. Here, some important literature reviews regarding composite slab behavior incorporating different profiles were discussed.
\end{abstract}

Keywords-Composite Deck Slab, Shear Connectors, Modern Constructions, Profiled Steel Deck.

\section{INTRODUCTION}

Composite steel-concrete structures are used widely in modem bridge and building construction. The fact that each material (steel or concrete) is used to take advantage of its best attributes makes composite steelconcrete construction very efficient and economical. However, the real attraction of composite construction is based on having an efficient connection of the steel to the concrete, and it is this connection that allows a transfer of forces and gives composite members their unique behavior. Shear connectors are provided to transfer load from composite steel deck to the steel beam. Shear flow forces have to be resisted by the shear flow strengths of the mechanical shear connectors that are used to tie the concrete component to the steel component. The shearing force at composite beams with profiled sheet is not introduced directly through the base of the shear connect, but is transferred onto the shank of the shear connector. The increase of load produces crushing of concrete in front of the shear connector and transfer of shearing force exclusively via bending.

\section{TYPES OF STEEL DECK}

\subsection{Box Profile 34/1000 Sheets (for roofing and cladding):}

Cladco Profiles 34/1000 trapezoidal sometimes referred to as box profile single skin sheet gives maximum sheet strength with 7 rigid profiles of $166 \mathrm{~mm}$ pitch across the sheet width and $34 \mathrm{~mm}$ profile height. It's made from wider coated steel strip to give a secure weather proof lap and gives $1000 \mathrm{~mm}$ actual width cover when lapped as shown in figure (1).

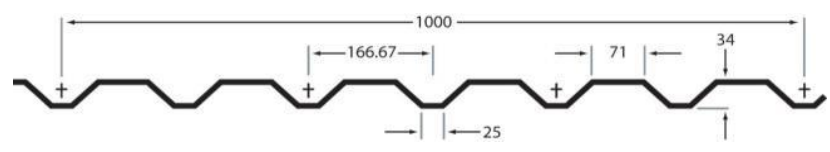

Fig.1: Box Profile 34/1000

\subsection{Box Profile 32/1000 Sheets (for roofing and cladding):}

Cladco Profiles 32/1000 trapezoidal sometimes referred to as box profile single skin sheet gives robust sheet strength with 6 profiles of $200 \mathrm{~mm}$ pitch across the sheet width and $32 \mathrm{~mm}$ profile height. Some users prefer the appearance of this profile as it has lower and less profiles. It's made from coated steel strip and gives 
$1000 \mathrm{~mm}$ actual width cover when lapped as shown in figure (2).

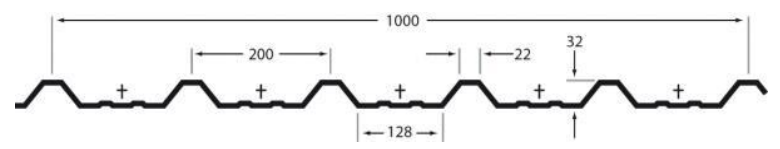

Fig.2: Box Profile 32/1000

\subsection{Corrugated Profile 13/3 (for roofing and cladding):}

Cladco Profiles traditional 13/3 'corrugated iron' profile. 13 corrugations of 3 inch $/ 76 \mathrm{~mm}$ round corrugation gives $3 \mathrm{ft} 3 \mathrm{inch} / 990 \mathrm{~mm}$ sheet cover when lapped as shown in figure (3).

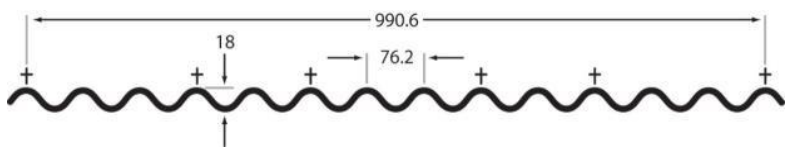

Fig.3: Profile 13/3

\section{PREVIOUS STUDIES}

Wang Yu Hang and NIE JianGua, 2015 [1], studied theoretical model for ultimate load carrying capacity of composite slabs cast with profiled steel sheets considering the relation between ultimate moment carrying capacity of the section and tensile force resisted by the profile deck sheet. Analytical study was carried out by considering two span continuous slabs subjected to one-point load, twopoint load and uniformly distributed load. Based on the developed stress diagram an equation was derived for all these three cases. The study was also carried out by experimentally testing the specimens considering same loading conditions to validate the theoretical work. The investigators state that the results of other, analytical and experimental study are found to be similar. It is recommended that though the $\mathrm{M}-\mathrm{K}$ method is convenient for designing the composite slabs, it cannot be used for direct practical approach it is repetitive in nature and this tends to uneconomical design. Hence, in this paper researcher suggested an alternative method for calculating ultimate load carrying capacity of the composite slab known as simplified calculation method. The method is based on the dimension less parameters considering both flexure and longitudinal failure but can be used only in case of uniformly distributed loading condition.

M. A. Bradford et al, 2011 [2], studied the long term effect due to shrinkage of concrete which will result in initial indirect strain in composite slab as creep in concrete is observed in initial stage after casting. The researcher derived anew for deflection and stress equation based on virtual work method by considering the partial shear interaction between concrete and steel sheet subjected to shrinkage straining. It was observed in experimental study that quantification of the shrinkage and partial interaction is seen in the uncracked area as it allows strain to be transferred through the depth of the slab due to difference in corrugation depths of the profile deck sheet. The results indicated that forecast response for the slab was complex as the combination of the shrinkage and partial interaction gave rise to the small concrete stresses which should be analytically studied for giving the application based structural mechanism.

M.E. A-H Eldib, 2009 [3], studied the behavior of twoway composite slab using finite element analysis in COSMOS/M26 software. The researcher compared one way and two way slabs using nonlinear material properties and full-scale models with varying parameters such as slenderness ration and slab aspect ratio. The analytical results were compared in respect of ultimate load carrying capacity, reaction distribution and deflection of composite slab. The side perpendicular to the ribs of profile deck sheet of a composite slab is usually the weaker side, whereas the side along the ribs is stronger. Hence, the study of behaviour of composite deck slab along the weaker side helps in enhancing the ultimate load carrying capacity of the slab. The investigators report that, though the slab is a two way slab its failure at ultimate load resembles as that of one-way slab, because value of load factor at serviceability limit and percentage of reaction is greater on weak side. However, Shear connectors and cold steel straps fixed at bottom steel deck prevents or say reduces the deflection and considerably increase the strength of composite slab.

Redzuan A. and W. Samuel, 2008 [4], studied new procedure to estimate the horizontal shear in which slab slenderness ratio is considered to be the predominant factor affecting the horizontal shear force. The researcher derived new equation based on force equilibrium method for deriving the relation between shear bond stress and end slip. The justification of the derived relation was also carried out with the conventional partial interaction method. The relation between shear bond stress and end slip was similar by both the methods. To validate the results of the analytical work experimentation carried out for bending test with two-point load bending test and slip observed was larger in compact slab than in slender slab. For full interaction slab shear bond and end slip curve was plotted along the vertical axis i.e. end slip does not occur for the slab with full interaction. While in partial interaction the shear bond is unchangeable. The researcher concluded that the shear bond property changes with 
change in combination of slenderness or geometry or material. For particular case for same material and geometry the only property that affects shear bond is slenderness. So most important property horizontal shear bond stress-end slip relation can be obtained from force equilibrium method which is very important for numerical analysis.

Emad El Dardiry and Tianjim Ji, 2006 [5], studied the dynamic behaviour of composite slab using isotropic and orthotropic plate model. The properties of section where kept same in both directions for isotropic model but different in orthotropic model. The analytical results of the study indicate that the mode shapes checked for each panel are either concave or convex though the complex behaviour is taken in consideration. However, the isotropic model proves to be slightly better than orthotropic model. In case of effect of boundary condition, orthotropic model proves to be stiffer and its effective thickness remains constant, while good performance was noted for isotropic plate where thickness varies from 5 to $6 \%$. In case of load combination less error was noted for isotropic plate i.e. 4 $\%$ and for orthotropic plate $10 \%$ was noted. Now eccentricities are considered to find effect on natural frequency and it was found that ratio of natural frequency for model with and without eccentricities vary from $74 \%$ to $78 \%$. Natural frequency is not sensitive to location of natural axis of slab and beam as far as eccentricity is considered. The composite slab contributes $16 \%$ of total stiffness of structure. The prediction of natural frequency is affected by the thickness of slab.

Marciukaitis et al; 2005 [6], studied the connection between profiles sheet and concrete directly affect the overall

deflection for the composite slab which directly depends on the shear stiffness due to connection. The researcher evaluated a new method to evaluate deflection of composite slab considering all the factors starting from loading to the ultimate moment. The connection between profile sheet and concrete is not rigid or stiff, but it is partially in contact with each other. The stiffness between the layer's changes with the action of external forces. As there are two different materials they will undergo different deformations under loading. Though there are shear deformations these deformations are largely governed by the difference in deformation. For small shear forces the slab behaves elastically and for larger shear forces the plastic behaviour is noted. According for elastic small deformations is noted and large deformations are seen in plastic behaviour. The equation where derived by considering two layers' composite member deflection. The researcher proved that there is no stiff bond between profile sheet and concrete. Hence partial stiffness should be considered while calculating deflection.

K. N. Lakshmikandhan et al., 2013 [7], have experimentally studied three types of mechanical connector and found that three connector schemes exhibited full shear interaction and produced a negligible slip.

Milan Veljkovic, 1996 [8], Studied and investigate analysis based on interaction characteristics evaluated from small scale tests has been shown to accurately describe the behaviour of composite slabs. The interaction characteristics considered are mechanical interlocking resistance, reduction of the mechanical interlocking due to strains in the sheeting and the friction at the support. The validation is, however, limited to comparisons with full-scale test on one particular profile. The load bearing resistance of slabs increases as the loading becomes more uniform when longitudinal shear failure governs. For one example where longitudinal shear failure governs, the increase of the resistance with respect to 2-point loading is $20 \%$, $30 \%$ and $40 \%$ for 4-point, 8-point and 16-point loading, respectively. All slabs have the same shear span. Due to a change of the failure mode, differences between the bearing resistances decrease as the span increases.

Hyeong-Yeol Kim, Youn-Ju Jeong, 2010 [9], investigated the ultimate behavior of a SCC composite deck slab system with profiled steel sheeting and perfobond rib shear connectors. Eight specimens were prepared and develop composite deck slab for girder bridges that spans longer but weighs less than conventional reinforced concrete slab, which were evaluated using empirical $\mathrm{m}-\mathrm{k}$ method. The ultimate strength under bending was at least $20 \%$ less than RC deck. The load carrying capacity is approx. 2.5 times greater, while concrete cracking load is 7.1 times greater with total weight $2.5 \%$ lesser.

Amar Prakash, N. Anandavalli, C. K. Madheswaran, J. Rajasankar, N. Lakshmanan 2011, [10] proposed nonlinear behavior of stud connected to steel-concrete composite girders numerically. 3D modeling through ABAQUS is analyzed. Specimen of $4 \mathrm{~m}$ length and width of $0.665 \mathrm{~m}$ with $3.8 \mathrm{~m}$ is simply supported. Maximum load observed was $360 \mathrm{kN}$ analytical to $330 \mathrm{kN}$ experiment outcome. The deflection obtained $136 \mathrm{~mm}$ analytical to $138 \mathrm{~mm}$ experiment outcome. Comparison of interface slips at three different values of deflection. 


\section{CONCLUSIONS}

The study until now was performed on analysing and predicting the behaviour of the composite steel structure with

concrete deck slab. Many researchers derived the expressions for deflection, ultimate moment, load carrying capacity and many more. Some questions regarding the behaviour of the slab for horizontal shear resistance and design requirements to achieve ductile failure. The optimization of the design for the proper combination of different corrugated profile sheets and type of mechanical interlocking to be provided is not yet completed. Though codal provisions are based on experimental results the finite element analysis of composite deck slab with nonlinear contacts between the profile, shear connectors and concrete is required to be studied for the complex composite action.

\section{REFERENCES}

[1] WANG YuHang \& NIE JianGuo, -Analytical Model for Ultimate Loading Capacities of Continuous Composite Slabs with Profiled Steel Sheets\|, Science China Press 2015.

[2] M. A. Bradford, R. I. Gilbert, R. Zeuner and G. Brockc, "Shrinkage Deformations of Composite Slabs with Open Trapezoidal Sheeting", Procedia Engineering (52-61), Volume 14, 2011.

[3] M.E. A-H Eldib, H.M. Maaly, A.W. Beshay, M.T. Tolba, "Modeling and Analysis of Two-Way Composite Slabs", Journal of Constructional Steel Research (1236-1248), Volume 65, 2009.

[4] Redzuan Abdullah, W. Samuel Easterling, "New Evaluation and Modeling Procedure for Horizontal Shear Bond in Composite Slabs", Journal of Constructional Steel Research (891-899), Volume 65, 2009.

[5] Emad El-Dardiry, Tianjian Ji, "Modeling of the Dynamic Behavior of Profiled Composite Floors", Engineering Structures (567-579), Volume 28, 2006.

[6] G. Marciukaitis, B. Jonaitis, "Analysis of deflections of composite slabs with profiled sheeting up to the ultimate moment", Journal of Constructional Steel Research (820 830), Volume 62, 2006.

[7] K. N. Lakshmikandhan, P. Sivakumar, R. Ravichandranand S. Arul Jayachandran "Investigations on Efficiently Interfaced Steel Concrete Composite Deck Slabs", Journal of Structures, 2013.

[8] Milan Veljkovic "Behaviour and Resistance of composite slabs Experimental and Finite Element Analysis" Lulea University of Technology, S-971 87 Sweden, 1996.

[9] Hyeong-Yeol Kim, Youn-Ju Jeong, "Ultimate Strength of a Steel-Concrete Composite Bridge Deck Slab with Profiled Sheeting", Engineering structures 32-534-546 2010.
[10] Amar Prakash, N. Anandavalli, C. K. Madheswaran, J. Rajasankar, N. Lakshmanan, "Three Dimensional FE Model of Stud Connected Steel-Concrete Composite Girders Subjected to Monotonic Loading", International Journal of Mechanics and Applications, 1(1): 1-11, 2011.

[11] EN 1994-1-1:2004, Eurocode-4, Design of composite steel and concrete Structures-Part 1.1, General rules and rules for buildings, 2004. 